\title{
Conceptual Design of Service Procurement for Collaborative Service Networks
}

\author{
Maik Herfurth and Peter Weiß \\ FZI Forschungszentrum Informatik, Haid-und Neu-Str. 10-14, \\ 76131 Karlsruhe, Germany \\ \{herfurth, weiss\}fzi.de
}

\begin{abstract}
In this paper we propose a conceptual model for e-procurement solutions for industrial services. Product-related services are of particular interest of companies and should be supported through an appropriate network strategy. However, in the service field, e-business solutions and current standards are still not or only partially considering specifications and related variables of services. We make an approach to develop a conceptual model which allows analyzing existing systems and to specify requirements by distinguishing four system levels. Services can be classified using criteria such as degree of tradeability, intangibility, degree of labor intensity or interaction, etc. In the context of collaborative networks and professional services another common variable is the level of customer contacts or interactions. Services looked at in this paper require close buyer-supplier relationships in nature, and motivate to apply collaborative networks as a strategy, as trust between buyer and seller can be seen as a central focus.
\end{abstract}

Keywords: Service procurement, e-business, collaborative networks, e-catalogues, service descriptions, product classification.

\section{Introduction}

Collaborative networks are emerging in service industries since many years [17]. Customers integrate service providers and suppliers through implementing appropriate collaborative strategies. The aim is the better integration of service suppliers into their business processes and information systems. Purchasing of services in real business practice still causes many problems.. Classification of services can be realized either from a customer or service provider perspective and can be done by applying top-down or bottom-up approach [3]. Hence, there is a need to develop electronic data transfer models and standards to foster the development and application of web-based information systems during a service negotiation and buying process between companies and their suppliers [5]. Service procurement is gaining more and more importance in industry. However, purchasing expends too much time and routine administrative work on the procurement of services [16].

\section{Collaborative Networks and Services}

Service procurement processes are still a source of high costs to companies, and due to its complex and heterogeneous purchasing processes. Large companies typically support 
up to now have tried to support those processes via the application of individual webbased information systems [5], [16]. In the context of collaborative networks and professional services another common variable is the level of customer contacts or interactions. Services looked at in this paper require close buyer-supplier relationships in nature, and motivate to apply collaborative networks as a strategy, as trust between buyer and seller can be seen as a central focus. "Industrial services have typically been divided into two broad categories: (1) maintenance and repair services, e.g., equipment repair, janitorial services, usually supplied under contract; and (2) business advisor services, e.g., legal, accounting, advertising, management consulting, typically new task-buying situations" [2]. In the remainder we focus solely on category (1). Complexity refers to the "level of technical training and difficulty associated with providing the service to the customer" [2]. "Elementary services are those related to products that are purchased frequently, are not essential to the industrial consumers primary functions, have low complexity, and do not require formalized service providers". [2]. Personal delivery describes "whether the service has to be delivered in-person by the service provider, whereas credence properties "refers to characteristics of the industrial product or service that makes it difficult to evaluate or understand" [2]. Thus, confidence in the service provider is essential "because the higher the credence properties of the service, the less likely the customer will understand or make an objective assessment of the quality of the service delivered" [2]. Tradeability of services depends on various other variables. Based on variables [3] classify services with regard to their appropriateness to be purchased and delivered online. Six service groups could be defined: (1) mass services, (2) professional services, (3) intellectual services, (4) credit services, (5) support services, (6) facility services. Three principal components to characterize service could be derived based on variables (shown in Table 1). Most variables describe the characteristics of the customer/provider relationship which is referred to as (A) "intimacy between service providers and customers". Further factors are: (B) "customer involvement on service good transactions" and (C) "importance of offline factors in the provision of service online goods". Whereby, C depends on "features of search goods" and "necessity of offline", B depends on "criticality for customer" and "necessity of membership relation". The emerging of e-catalog standards the product search can be used in a very different and improved matter [4]. Searching and purchasing of services necessitates the provision of electronic service descriptions and specifications, however, today it is still an unsolved problem for complex service. Complex services are offered and delivered in facility-oriented and product-related service industries such as maintenance, repair, disposal, etc. Services of this type have intangible and tangible elements and are typically exchanged in interaction processes where buyers and sellers are closely integrated [3]. Interactions include problem analysis and diagnosis to configure required services. To facilitate buying of services electronically requires product catalogues to find, compare, select, order and invoice complex services. Today, those systems are supporting mainly simple services with more tangible than intangible nature of service act. Customization and service packages are seen as adequate means to overcome current limitations of collaborative systems. Variables can be grouped into traditional service variables, online goods variables and variables relevant to both. "Necessity of membership relation" can be seen of high relevance in the context of collaborative networks. It signifies customer expectations as to the type of relationship with the service organization, "e.g. whether it is involves a membership relationship or not" [3]. 
Table 1. Variables for classification [3]

\begin{tabular}{|l|l|}
\hline Traditional service variables & - Criticality for customer \\
& - Importance of professional knowledge \\
& - Degree of labor intensity \\
& - Degree of interaction \\
& - Degree of customer contact \\
Online goods variables & - Necessity of membership relation \\
& - Frequency to purchase \\
& - Features of search goods \\
Variables relevant to both & - Price \\
& - Degree of customization \\
\hline
\end{tabular}

Collaborative networks would allow decreasing transaction costs and agreeing on common standards and collaborative processes by fostering trust and quality of relational ties [2]. Configuration of collaborative processes depend on nature of rendered services (characterized through variables as shown in table 2 as well as quality of network ties and relationship. Latter are supposed to have strong influence on required interaction processes and transaction costs. Services offered or delivered electronically require specific characteristics. Services appropriate for e-commerce need to be standardized to provide them online. Thus, service industries are starting to offer more and more services electronically, which in turn requires implementing appropriate strategies [3]. Strategies depend on the type of service offerings.

\section{Conceptual Model for Service Procurement}

In our paper we specifically look at the procurement of industrial professional Services in Collaborative Networks. Procurement processes are defined by specific transaction phases which are looked into in the remainder. Especially, decision and control processes are related to procurement of direct material. This has negative effects on process costs, which increases through increased interactions e.g. manual clarification of identified differences verifying invoice of service suppliers against invoice, or invoice against delivery note and against order. In the context of procurement of industrial professional services new business documents and transactions logics are required. Delivery note for example is replaced by the bill of quantities and approval protocol. Collaborative service networks require reference models and standardized transaction documents to reduce costs and to internalize supplier services. Long procurement times and above related inefficiencies and problems have the effect that purchasing of services is often bypassing official purchasing process through so called "maverick buying". It causes greater capital commitment and low transparency of sales volumes and spending [16]. We present a conceptual model for service procurement in collaborative networks. Our model (figure 1) describes four different abstract layers to comprise service procurement in collaborative networks. The highest level $A$ of the model is defined as the business operational view level to describe and define requirements for the organization and business for service procurement between clients and service providers. 


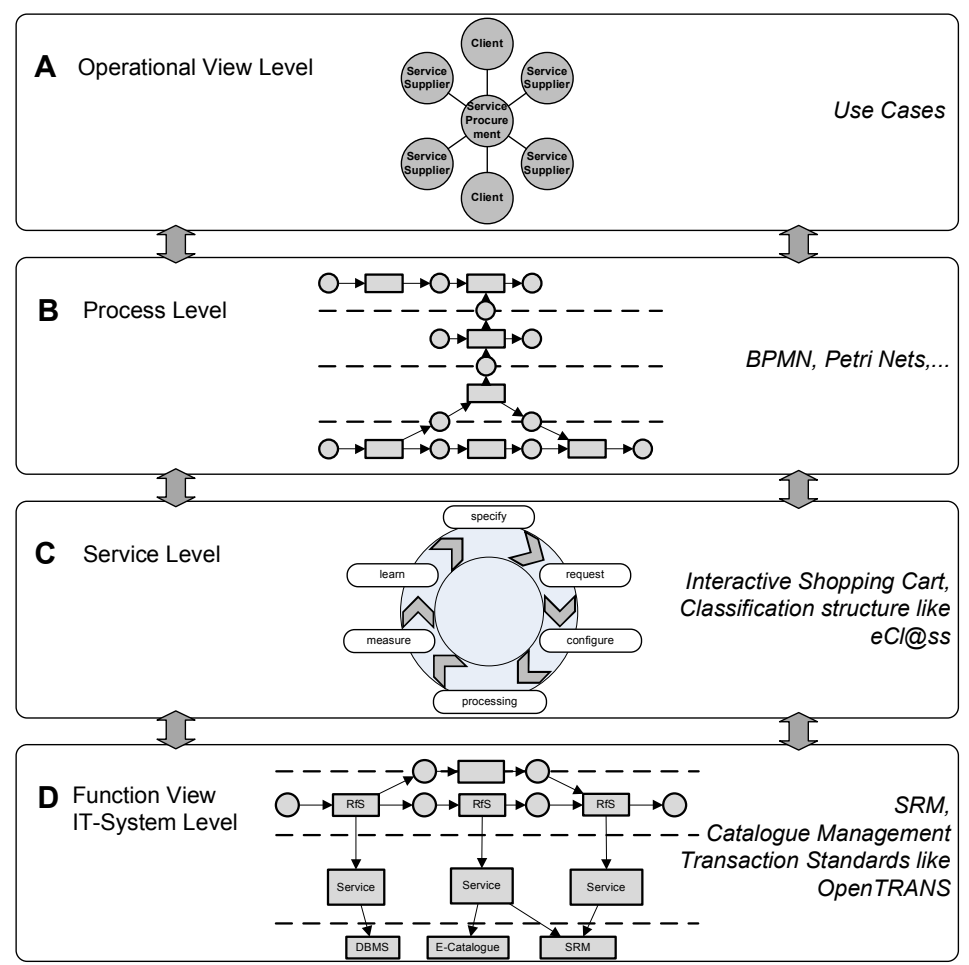

Fig. 1. Conceptual Model for Service Procurement

It defines the business model and the relationship between participating actors in the collaborative network. Therefore it can be defined by use case to identify the reality of e-procurement for services. The next level $B$ is called process level. Business processes for service procurement are represented. It defines the alignment of processes and reference process models with the functional perspective and the use cases can be mapped on business processes. An implementation of the process level could be the use of formal modeling languages. The level $C$ is called service level. The service level defines phase-oriented persistent states transition types of a service. The different state transitions are request, specify, configure, processing, measure and learn. The status request describes the definition of the service. While the specification of the service, the service will be in the specification status. The negotiating of the service defines the configure status. The execution of the service formulates the processing status. The status after the processing will be the measurement status. The learn status saves the final status. The saved status of a service can be used for following transactions and serves as a frozen status to draw experiences for this service type. The status types are following a continuous cycle along a service transaction process and oriented at transaction phases aligned with the eight phases service transaction model. The state transition types define the status of a service at different stages. The interactive shopping cart [13] could be an implementation of this level. Level D is the system level and describes the software system functionality view of different enterprise software systems. On the system level, we build up different business software 
system like SRM or catalogue management systems. The conceptual model for service procurement allows us to structure service procurement in different perspectives and views. The conceptual model for service procurement is a holistic model for service e-procurement. The different levels are influencing each other and are dependant. Requirements are defined on level $\mathrm{A}$ and will have an influence on the other levels. With this model, we are able to structure service procurement and assign terms and definitions. An important issue is the allocation of standards. By using our conceptual model, we are able to assign important procurement standards and demonstrate the influence of these standards. In Fig. 1, we are giving examples of elements in the different phases.

Additionally transaction phases of service differ from material process phases. This is another specific characteristic of service processes and important for the electronic transaction of services. Interfaces within phases are collaborative interfaces between actors. These interfaces are needed for interaction and information exchange. The corporate interfaces are decisive for efficiency, effectiveness and performance of the collaboration and interaction between actors. Theses interfaces are missing harmonization and standardization which leads to problems for the whole transaction process. Besides these corporate interfaces, interfaces between transaction phases are existing. These interfaces can be internal or corporate interfaces. Information is exchanged within companies by internal interfaces.

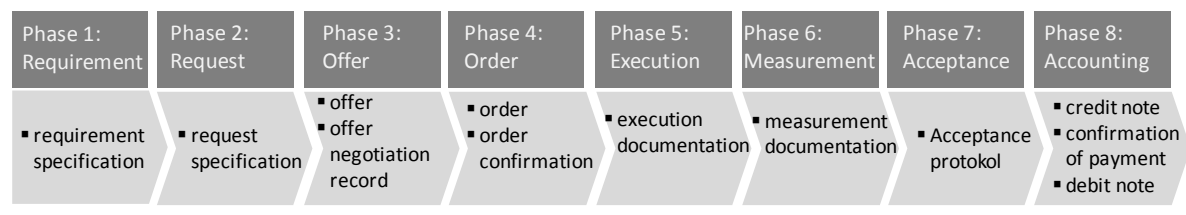

Fig. 2. Eight Phases Service Transaction Model

Corporate interfaces between transaction phases are result-oriented. At the end of every transaction will be a phase-oriented result by which the phase can be defined as concluded. The eight phases service transaction model defines typified properties of service processes. Fig. 2 shows the eight phases service transaction model with the specific service phases. The phase-related results are listed. The results document each phase and are exchanged between the actors.

\section{Description of Services}

For transaction in the content of e-Business a unique description of services is required. The description of service can be defined on level B of the conceptual model (Fig. 1). In service networks, different companies collaborate in order to transact services. The eight phases transaction model defines the structure of the transaction of services. Within collaborative service networks, also called value added networks, the collaboration occurs on a $n: m$-relationship: several service providers interact together with several service requesters. In [11], [12], [13] we presented a Meta model for the description of services. For our conceptual approach, we use an XML-based description of services. 
Additionally, material positions like commodities and durables or tools are assigned. Also materials are assigned to service positions. Therefore this shows the typical characteristic of industrial services. Service units can be used to describe and define specific service-oriented business document types. Service units can be cumulatively represented in service specifications.

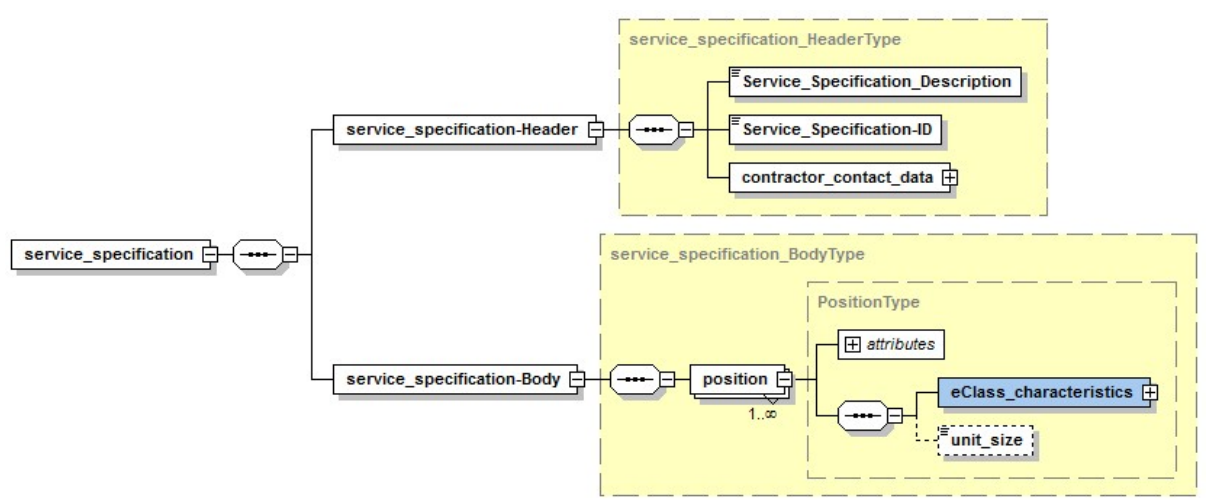

Fig. 3. Service Specification Structure

Service specifications are contract-based collections of service units as a base of businesses between clients and contractors and define individual sub positions of service units. Service specifications can be defined individually for an order or on the basis of a frame contract. Figure 3 shows the XML scheme of the service specification. The header part defines specific Meta information about the service specification, a unique ID of the service specification and related information about the contract partner. In the body part, the description of services is defined. The element type position defines services.

\section{Transaction Standards for Service Procurement}

Transaction standards can be used for the specification of business documents for e-commerce. Out of different data types, business transaction documents can be defined. Many transaction standards are based on the principle of core components technical specification $\left(\mathrm{CCTS}^{1,2}\right)$. The CCTS approach shall improve the interoperability between e-business applications and business partners. The use of Core Components in

${ }^{1}$ Core Components are a library of basic atomic or composed data types with a unique description and are defined by UN/CEFACT. Core Components are modules for the development of semantic correct and significant packages for the exchange of business information. Different organizations are standardizing Core Components explicitly or they are implicitly part of transaction standards. The standardization organization OASIS is maintaining the ebXML Core Components Technical Specification (CCTS).

2 The specification ISO/TS 15000-5 ebXML (Electronic Business Extensible Markup Language) Core Component Technical Specification, Version 2.01 (ebCCTS) was published in September 2005 as an ISO standard. 
a specific business context, it is called Business Information Entities (BIE). For the electronic description and transaction, a specific description and transaction format is needed. Service-oriented business document transaction types have to be supported. The description of single services (service objects) should be based on a classification structure for a unique identification of services to use the advantages of classification systems. In our conceptual model of service procurement, transaction standards can be classified on level D. Existing transaction standards are the Universal Business Language (UBL) [15], openTRANS [8], GS1-XML [10], GAEB DA XML [9] and myOpenFactory [16].

Table 2. Comparison of Transaction Standards

\begin{tabular}{|c|c|c|c|c|c|c|}
\hline \multirow[t]{2}{*}{ Document types } & \multicolumn{6}{|c|}{ Transaction Standards } \\
\hline & $U B L$ & $\begin{array}{c}\text { open- } \\
\text { TRANS }\end{array}$ & $\begin{array}{l}\text { GS1- } \\
X M L\end{array}$ & $\begin{array}{c}\text { open- } \\
\text { Factory }\end{array}$ & $\begin{array}{c}G A E B \\
X M L\end{array}$ & $\begin{array}{l}\text { ebus } \\
X M L\end{array}$ \\
\hline service specification & & & & & $\sqrt{ }$ & $\sqrt{ }$ \\
\hline e-catalogue structure & & $\sqrt{ }$ & & & & $\sqrt{ }$ \\
\hline request & $\sqrt{ }$ & $\sqrt{ }$ & & $\sqrt{ }$ & $\sqrt{ }$ & $\sqrt{ }$ \\
\hline offer & $\sqrt{ }$ & $\sqrt{ }$ & & $\sqrt{ }$ & $\sqrt{ }$ & $\sqrt{ }$ \\
\hline frame contract & & & & & & $\sqrt{ }$ \\
\hline order & $\sqrt{ }$ & $\sqrt{ }$ & $\sqrt{ }$ & $\sqrt{ }$ & $\sqrt{ }$ & $\sqrt{ }$ \\
\hline order confirmation & & $\sqrt{ }$ & $\sqrt{ }$ & $\sqrt{ }$ & $\sqrt{ }$ & $\sqrt{ }$ \\
\hline measurement document & & & & & & $\sqrt{ }$ \\
\hline acceptance protocol & & & & & & $\sqrt{ }$ \\
\hline debit note & $\sqrt{ }$ & $\sqrt{ }$ & & $\sqrt{ }$ & $\sqrt{ }$ & $\sqrt{ }$ \\
\hline payment confirmation & & & & & & $\sqrt{ }$ \\
\hline credit note & $\sqrt{ }$ & & & & & $\sqrt{ }$ \\
\hline
\end{tabular}

We compared these transaction standards and we develop a new approach based on the requirements for the electronic transaction of industrial services. In Table 2, the analyzed transaction standards are compared. None of these standards defines all document types needed for the electronic data exchange of the transaction of industrial services. The structure of all standards differs. By the orientation on existing standards, we try to establish a solution with a high acceptance on the market which aims to be standardized. Our approach is compatible towards the existing presented transaction standards and can be transferred by XML converters.

\section{Results}

In this paper we presented a new holistic approach by a conceptual model of service procurement. The model provides a comprehensive view on service procurement. Finally identified terms and definitions can be described by this model and be assigned on the different levels. Based on this model, we provided solution approaches for the different levels and demonstrated the dependent elements of services procurement. For the electronic procurement of services, the specification of services has to be formally be defined. We proposed a structure for the specification based on XML. Transaction standards describe important business document types. Depending on the 
requirements for service procurement, we defined a new proposal for a transaction with service-specified document types. Transaction standards and business processes are related. In service procurement, transaction processes and business documents are interweaved by a choreography of processes based on service-specific business document types.

\section{References}

1. ECl@ss: International Standard for the Classification and Description of Products and Services (2009), http: / / www . eclass . eu/

2. Boyt, T., Harvey, M.: Classification of Industrial Services: A Model with Strategic Implications. Industrial Marketing Management 26, 291-300 (1997)

3. Lee, S., Park, Y.: The classification and strategic management of services in e-commerce: Development of service taxonomy based on customer perception. Expert Systems with Applications 36, 9618-9624 (2009)

4. Döring, S., et al.: Evaluation and optimization of the catalog search process of eprocurement platforms. Electronic Commerce Research and Applications 5, 44-56 (2006)

5. Gomes Campelo Filho, E.: Analysis of Current Supplier Relationship Management Practices: A Solution Proposal, Dissertation University of Karlsruhe (2009)

6. Meier, A., Stormer, H.: eBusiness \& eCommerce: Management der digitalen Wertschöpfungskette. Springer, Berlin (2009)

7. BMEcat eBusiness Standardization Committee: BMEcat 1.2 (2005), http://www . bmecat. org

8. eBusiness Standardization Committee: openTRANS 2.1 (2009), http: / / www . opentrans.org

9. Bundesamt für Bauwesen und Raumordnung, DIN: GAEB DA XML 3.1 (2009), http: / / www.gaeb.de/produkte505.php

10. GS1 Germany: GS1 XML-Standards 2.7 (2009), http://www.gs1-germany . de/content/standards/ebusiness/gs1_xml/index_ger.html

11. Herfurth, M., Meinhardt, A., Schumacher, J., Weiß, P.: eProcurement for Industrial Maintenance Services. IFIP Advances in Information and Communication Technology, vol. 307. Springer, Boston (2009)

12. Herfurth, M., Weiß, P.: E-Procurement for Industrial Maintenance Services. In: eChallenges 2009, Istambul/Turkey (2009)

13. Herfurth, M., Kern, R., Rudolf, C., Weiß, P.: Reducing the complexity of Services: a new Approach to Service e-Procurement. In: Proceedings of the Multikonferenz Wirtschaftsinformatik MKWI 2010, Göttingen/Germany, (2010)

14. Benz, J., Höflinger, M.: Logistikprozesse mit SAP. 2. Auflage. Vieweg (2008)

15. OASIS: Universal Business Language (UBL) v2.0 (2006), http://docs.oasisopen . org/ubl/os-UBL-2.0/UBL-2 .0.html

16. myOpenFactory, DIN PAS 1074: myOpenFactory 4.0 (2009), http: / /myopenfactory.com/products-myopenfactory.html

17. Camarinha-Matos, L.M., Paraskakis, I., Afsarmanesh, H. (eds.): Leveraging Knowledge for Innovation in Collaborative Networks, 10th IFIP WG 5.5 Working Conference on Virtual Enterprises, PRO-VE 2009, Thessaloniki, Greece, October 7-9 (2009) 